\title{
O infantil na constituição subjetiva: restos, escrita e narrativa
}

\author{
Germano Quintanilha Costa*1 \\ Sonia Leite*2
}

\begin{abstract}
$O$ artigo descreve as trilhas do processo de constituição do psiquismo, como processo de inscrição de traços e da construção de um registro. Para tanto são introduzidos alguns aspectos fundamentais da teoria de Lacan: a falta do objeto, o traço, a letra, o significante, a repetição e o gozo. O objetivo principal é demonstrar que no campo da letra, no litoral entre o significante e o gozo, é possível delimitar com maior precisão o real estatuto da noção de infantil para a teoria e para a clínica psicanalítica, distinguindo-o, simultaneamente, da noção de infância.
\end{abstract}

Palavras-chave: Infantil, infância, inscrição, gozo

${ }^{* 1}$ Universidade Federal Fluminense - UFF (Niterói, RJ, Br).

*2 Universidade do Estado do Rio de Janeiro - UERJ (Rio de Janeiro, RJ, Br). 


\section{Introdução}

Trabalhar com a noção de infantil na psicanálise requer que sejamos capazes de pensá-lo sob o prisma daquilo que constitui o cerne da psicanálise: o inconsciente. Em sua trajetória na construção de uma teoria do aparelho psíquico é marcante o modo como Freud compreendeu a importância fundamental dos primeiros anos de vida para a constituição psíquica. Esse tempo introduz na psicanálise uma questão fundamental para a práxis psicanalítica: a infância e o infantil seriam perspectivas homólogas ou introduziriam distintos pontos de vista para uma teoria do sujeito? Em nossas investigações iniciais sobre o tema ${ }^{1}$ temos podido depreender que a infância e o infantil são conceitos que se tocam, porque ambos estão implicados nas origens e no funcionamento do psiquismo, porém dizem respeito a concepções com estatutos bastante distintos.

É a partir da noção lacaniana do tempo lógico — distinto do tempo cronológico - que essas duas concepções podem esclarecer como se efetuam as marcas no aparato psíquico de modo que num a posteriori viabilizam o advento da linguagem tornando o sujeito capaz de se dizer e se narrar. Tendo em vista o processo de constituição do psiquismo, como inscrição de traços e da construção de um registro, vamos introduzir, aqui, alguns aspectos fundamentais da teoria de Lacan: a falta do objeto, o traço, a letra, o significante, a repetição e o gozo. Nosso objetivo é demonstrar que é no campo da letra, isto é, no litoral entre o significante e o gozo, que podemos delimitar com maior precisão o estatuto e o alcance do infantil para a teoria e a clínica psicanalítica distinguindo-o, simultaneamente, da noção de infância.

${ }^{1}$ Trata-se de um projeto de pesquisa, em nível de doutoramento, inserido no Programa de Pós-Graduação em Psicanálise da Universidade do Estado do Rio de Janeiro. 


\section{O sujeito em Lacan}

Comecemos por pensar a constituição do sujeito. Com Lacan podemos dizer que o sujeito não nasce e não se desenvolve, ele se constitui. É somente ao longo de uma série de processos lógicos, envolvendo a relação do infans (aquele que não fala) com o Outro, que este poderá vir a se contar e a se narrar como sujeito.

Fazendo uso de recursos linguísticos (cadeia significante, metáfora, metonímia) e matemáticos (topologia e lógica), Lacan pôde formular uma teoria do sujeito através dos processos de alienação e separação quando especifica as relações possíveis entre o sujeito e o campo do Outro, deixando claro que, apesar de o sujeito ser um efeito do significante, por outro lado, ele possui sua causa no objeto $a$.

Num primeiro tempo, o sujeito é produzido por sua alienação ao aparelho da linguagem. Interessado em demonstrar que a divisão do sujeito e o advento do inconsciente são processos que acontecem pela ordem do significante, Lacan elabora uma teoria sobre o processo metafórico do Nome-do-Pai. Ao estabelecer os três tempos do Édipo, demonstra que a metáfora paterna é responsável pela constituição do psiquismo na medida em que possibilita o acesso ao simbólico a partir de uma substituição significante em relação ao enigmático desejo materno (Lacan, 1957-1958/1999).

No entanto, a continuidade de seu ensino vai estabelecer que o sujeito não é todo determinado pelo Outro e pelo aparelho significante. A partir de $O$ seminário, livro 11 (1964/1973), a distinção do sujeito é enfatizada pelo viés de uma segunda operação: a separação. Evidenciando a existência de uma falta no coração do significante, Lacan aponta que no discurso do Outro existe uma impossibilidade de se dizer tudo completamente. Apesar de o corpo pulsional do bebê ser atingido pelos significantes, existe entre a criança e o Outro uma cota de não sentido, de gozo que não pode ser dita pela palavra. Considera, portanto, que a divisão do sujeito deixa um resto - o objeto $a-$ e que esse processo não é fruto somente dos efeitos da simbolização, mas, também, por conta da dimensão real da pulsão.

\section{A inscrição do bebê no campo do significante}

Considere-se este primeiro momento em que o infans se aliena ao Outro do significante. A relação do advento do sujeito com o campo da linguagem é tão profundo que Lacan chega a afirmar que "a alienação é o destino de todo ser falante" (Lacan, 1964/1973). É somente pela via da alienação ao discurso do Outro que o infans poderá sair de seu estado de desmontagem pulsional para a construção de um corpo habitado por uma imagem identificatória e por um 
discurso simbólico. Os cuidados maternos diante das necessidades do bebê constituem o palco principal em que se desenrola a cena do desejo, da pulsão e da linguagem. Tais cuidados estão para além do fornecimento dos cuidados físicos, pois, ao atender ao bebê, o Outro Materno fornece também suas fantasias, seu discurso e os enigmas de seu desejo.

Desse modo, podemos dizer que os efeitos da submissão do bebê à linguagem pelo discurso do Outro é o que permite a formação do inconsciente e a constituição do sujeito desejante. São nos atos de fala dirigida ao organismo neonato que essa antecipação subjetiva confirma a existência de um bebê (Neves \& Vorcaro, 2011). O Outro primário, ao reconhecer e articular as manifestações corporais da criança, permite, simultaneamente, a transposição de suas manifestações para a ordem da linguagem, e a criança, ao se alienar a esses sentidos, que vêm do campo do Outro, precipita-se numa antecipação identificatória, de onde vai extrair a matriz imaginária e simbólica para construir o registro do eu.

Quando alguém encarna a função de receber o endereçamento dos apelos do bebê, este pode, efetivamente, sair do simples estado da necessidade e adentrar para o registro da demanda. O choro já inscrito na demanda não se destina apenas à satisfação da fome, mas sim a uma convocação da presença do Outro, ato pelo qual começa a se fazer comparecer para os agentes de seus cuidados.

Uma questão fundamental, que aí se coloca, é que mesmo quando a resposta que advenha compareça como mutismo, algo aí se institui, ou seja, "há que se supor que esse sujeito, de alguma maneira, foi marcado pela presença do Outro e articulou alguma concatenação para falar e silenciar" (Neves \& Vorcaro, 2011, p. 280). Pode-se, portanto, apontar aí a implantação de um primeiro significante no organismo, em que "o sujeito recebe a sua primeira assinatura, signum, em sua relação com o Outro" (Lacan, 1958-1959).

A importância dos cuidados primários é que os gestos dirigidos ao bebê, pelo fato de serem portadores de significação, permitem que as palavras sejam veiculadas, possibilitando à linguagem circular, fazendo, portanto, um enlaçamento do real do organismo ao campo simbólico e imaginário.

Interessa-nos, agora, aprofundarmos a questão de como essa inscrição na linguagem aponta para uma rasura e uma perda necessárias para que o significante possa ser apropriado pelo sujeito.

\section{Das experiências vividas às inscrições constituintes}

Considerando que o humano é desprovido de um código, que de forma inata e instintiva possa dar um valor àquilo que lhe chega através da percepção, é somente a partir das experiências vividas que se produzirão inscrições psíquicas 
capazes de inaugurar um aparelho psíquico. Estabelece-se, a partir disso, um complexo sistema de representação, que funcionará como memória. A esse respeito, Jerusalinsky (2014) realiza um estudo da obra freudiana destacando três pontos centrais.

Primeiro. O psiquismo não pode ser comparado a uma tábula rasa na qual todo estímulo externo se inscreve, por isso nem tudo aquilo a que estamos expostos produz, necessariamente, uma marca. Freud compreendia que o aparelho psíquico tinha uma incrível capacidade de evitar estímulos externos, mas a partir do momento em que não pode fugir dos estímulos internos, reconhece que essas primeiras experiências são as que originalmente ganham inscrição. O importante a se frisar é que as satisfações dessas necessidades endógenas só podem ocorrer através da assistência alheia de uma pessoa específica que atribui ao choro do bebê uma intenção de comunicação (Freud, 1895/1996).

Segundo. Mesmo considerando as experiências que marcam o bebê, precisamos reconhecer que nem tudo dessa experiência vai se inscrever. $O$ que se inscrevem são traços e estes, por sua vez, não guardam correspondência representacional fixa com os objetos do mundo, ou seja, não possuem uma correspondência direta com o objeto referente, nem tampouco uma significação intrínseca. Isso se comprova desde os primórdios da psicanálise, quando Freud já estabelecia o conceito de traço mnêmico. Em o "Projeto para uma psicologia científica" (1895/1996), ele aponta que as experiências vividas não são registradas integralmente, pois, a partir delas, se recortam quantitativa e qualitativamente algumas percepções que passam a ser inscritas como traços. A inscrição, portanto, não é uma marca que se assemelha à realidade, nem uma cópia direta da experiência. O conceito de traço implica mais uma concepção de sulco do que de uma "tipografia impressa". O traço enquanto inscrição é um rastro, um vestígio deixado por uma passagem e não uma ocupação positivada. Essa noção de rastro e sulco remete às vias de facilitação, trilhamentos, como indica Freud, que deixam uma maior permeabilidade para a passagem dos investimentos. É a partir disso que podemos pensar na repetição como certos caminhos que vão passar a se impor ao psiquismo, na medida em que certas vias já se encontram facilitadas, já trilhadas e sulcadas pela inscrição.

Terceiro. Se nem tudo se inscreve e o que se inscreve diz respeito a um traço, é preciso considerar que nem tudo o que se inscreve no aparelho psíquico pode ser evocado, e por isso o esquecimento é fundamental para o advento do sujeito. Na "Carta 52" (1896/1996), Freud afirma que nem tudo o que está inscrito em um sistema psíquico pode passar para o outro. Entre os sistemas psíquicos operam transcrições e nem todas as transcrições são transcritiveis. Isso faz com que nem tudo que se apresenta, a partir dessas inscrições, possa se tornar legível. As formações do inconsciente apresentam-se como profundamente enigmáticas 
para o sujeito, pois uma parte delas poderá ser articulável pelos significantes, através da associação livre, enquanto outra mergulhará na dimensão do ilegível, constituindo aquilo que Freud chamou de "umbigo do sonho".

Essas observações sobre o aparelho psíquico sob a ótica de um sistema de inscrição de traços é fundamental para nosso estudo. Se o infantil conjuga algo que estava em jogo nas origens do sujeito que ainda se faz presente e atual na vida do adulto, então, como já afirmamos, ele precisa ser pensado pelo viés da teoria do inconsciente. Pensar o inconsciente, por sua vez, é pensar nas questões relativas à inscrição de traços e rasuras responsáveis por viabilizar a constituição de um aparelho de linguagem. Seguindo esta lógica evidencia-se que o avanço de nossa discussão em torno do infantil depende de uma compreensão clara do modo como Lacan situou o conceito de letra e sua atuação na constituição do sujeito.

$\mathrm{O}$ conceito de letra aparece em vários momentos do ensino de Lacan, sofrendo algumas reformulações. A primeira conceituação aparece no texto "A carta roubada" (1957/1998), em que o postulado do inconsciente estruturado como uma linguagem expõe um lugar decisivo ocupado pela letra; letra como aquilo que está superposto ao significante. Aqui o termo lettre associa-se à expressão " a letter, a litter", "uma carta/uma letra, um lixo". Com isso, Lacan evidencia uma dimensão outra, para além do caráter mensageiro da carta. $\mathrm{O}$ destino da carta extrapola sua função de levar uma mensagem, pois ela cumpre seu destino depois que passa de mão em mão, sendo deixada, largada, e gerando, com isso, efeitos.

Posteriormente, a letra surge no texto "A instância da Letra no inconsciente - ou a razão desde Freud" (1957/1998), quando se configura como a materialidade do significante, como "estrutura essencialmente localizada no significante" (p. 481). A terceira conceituação está presente nas articulações de $O$ seminário. Livro 6. O desejo e sua interpretação e de $O$ seminário. Livro 9. A identificação. As últimas conceituações aparecem em "Lituraterra" (1971/2006) e em $O$ seminário. Livro 20. Mais ainda (1972-1973/1985).

Se o tema da letra perpassa, portanto, uma gama de conceituações realizadas por Lacan, por motivos de recorte teórico, a condução de nosso estudo vai explorar as suas últimas conceituações, justamente por permitir uma elucidação da inscrição do infans no campo do significante e da queda do objeto que marca uma ausência.

\section{A produção do significante: inscrição de um traço e seu apagamento}

Encontramos no $O$ seminário. Livro 6. O desejo e sua interpretação importantes apontamentos que nos ajudam a compreender como a constituição subjetiva 
é correlata da produção necessária de uma perda, ou melhor, de um apagamento que permite o advento do significante. Lacan propõe que a constituição do significante ocorre em três tempos: a pegada, seu apagamento e o rastro, deixado pelo apagamento. É, portanto, pela sucessão desses três momentos que a inscrição psíquica, enquanto letra, será portadora de um enigma que, posteriormente, se articulará em um funcionamento significante.

Lacan evoca uma cena em que Robinson Crusoé encontra a pegada do personagem "Sexta-feira" e depois de apagá-la introduz em seu lugar um "X". Ao falar do passo e do rastro do passo de Sexta-Feira, Lacan (1958-1959) explica que o significante não começa no rastro, pois "não é o rastro apagado que constitui o significante", mas "é algo que se coloca como podendo ser apagado que inaugura o significante" (p. 95). Continuando, ele afirma que Robinson Crusoé apaga o rastro do passo de Sexta-Feira, mas para manter tal lugar ele faz no mínimo um " $X$ ", quer dizer, uma barra e outra barra sobre esta, o que configura o significante específico. E o significante específico é "algo que se apresenta como podendo ser ele próprio apagado e que justamente nesta operação de apagamento como tal subsiste" (p. 95).

Os apontamentos desse seminário permitem reconhecer esses três tempos que produzem uma inscrição. Primeiro, temos a pegada como marcas deixadas pela passagem de um objeto. Depois temos o apagamento dessas pegadas. Por fim, temos um rastro produzido pelo apagamento, surgindo daí um registro, uma inscrição de outra ordem.

Através dessa cena, Lacan estabelece que é o apagamento, a rasura da pegada que vai possibilitar o funcionamento da letra enquanto significante, que dá lugar a uma "representação não representacional", ou seja, "um sistema de inscrição e representação que não está colado nem ao objeto referente em si, nem à imagem do objeto, e tampouco previamente ao conceito de objeto" (Jerusalinsky, 2014, p. 91).

Em O seminário. Livro 9. A identificação (1961-1962) Lacan articula a história da escrita e da letra, enquanto inscrição psíquica, forjando o conceito de traço unário (primórdio da identificação simbólica). A partir desses apontamentos é possível compreendermos que o traço é a forma mais simples de marca, o que implica necessariamente a perda do objeto que está na origem do significante. O traço unário é esclarecido sob o exemplo de um osso pré-histórico no qual os homens primitivos talharam uma série de traços verticais. $\mathrm{O}$ traço unário envolve a produção de algo que não guarda relação com a coisa em si, mas que, a partir do $u m$, inaugura uma contagem, surgindo daí uma série simbólica para o sujeito. Assim, a inscrição desse traço produz uma divisão no sujeito, pois, por um lado, ele permite que o sujeito se reconheça nesse traço, nesse um que se conta, porém, por outro lado, tal inscrição carrega a dimensão da perda do objeto. 
A relação do traço unário com a letra tem uma importância fundamental para o estudo do infantil, como também para a práxis psicanalítica com crianças, justamente porque essa relação sinaliza os primórdios da instauração da linguagem e da perda do objeto. Introduziremos esses três tempos através da experiência do infans.

O primeiro tempo é o momento em que surge para o bebê a inscrição mnêmica de uma primeira experiência de satisfação. Trata-se na verdade da inscrição de uma primeira marca recebida pelo sujeito vindo do Outro. Esses traços constituem os elementos mínimos de um enigma, eles marcam o tempo primeiro da instalação do significante, "ofertando-se como suporte material para que sobre ele a operação se desdobre" (Fragelli, 2002, p. 59). O bebê, no início de sua vida, mais do que contar é levado em "conta por outro", e por isso a instauração do traço unário, da referência simbólica, depende do laço com o Outro materno, “(...) que sustenta as séries para o bebê, (...) que faz dos objetos - papinha, leite, cocô, xixi, sono, meleca - traços que contam em uma série" (Jerusalinsky, 2014, p. 133).

Num segundo tempo ocorre um apagamento, ou uma rasura, fazendo com que essa primeira marca se torne e permaneça inconsciente. Trata-se de um apagamento do traço que irá permitir que o significante se constitua. Essa operação pode ser identificada como o recalque originário, processo que impede que o traço tenha acesso à consciência. Para Lacan é a partir daí que o "S " é instituído, o primeiro significante do sujeito. Todos os significantes que vierem em seguida a esse apagamento, por uma linha associativa, e que estiverem remetidos ao $S_{1}$, serão recalcados, decorrendo daí que "esses significantes formam uma cadeia, iniciando a operação significante, imprimindo um texto ao inconsciente" (Fragelli, 2002, p. 62).

Por fim, temos um terceiro tempo no qual o sujeito poderá enfim se dizer e se narrar, ato este que só é possível por realizar uma interpretação daquelas marcas que foram inscritas. Nesse momento o sujeito se constitui na medida em que, também, pode dar uma significação própria às marcas recebidas. É importante frisarmos que o operador que permite essa façanha ao sujeito é o significante do Nome-do-Pai.

O Nome-do-Pai se destaca por sua função estruturante, porque é ele quem vai confirmar a divisão do sujeito pela linguagem e que o submeterá à lei simbólica. Isso acontece porque ele interdita o desejo materno e possibilita à criança um lugar diferente daquilo que falta à mãe. Essa interdição representa uma barra ao gozo que faz surgir a cadeia significante.

É importante delimitar a diferença entre rastro, traço e significante. $\mathrm{O}$ fato de um rastro poder ser negado materialmente permite que se torne um traço ou uma letra. O traço é algo fixo, sendo equiparável a uma forma material 
compatível com a representação-coisa e com a ideia de traço mnêmico visual. É somente num terceiro tempo que ocorre a negação do traço pelo funcionamento do recalcamento, surgindo, assim, o significante, volátil, que jamais pode ser apagado. A diferença fundamental entre traço e significante é que eles remontam a estruturas diferentes de linguagem; enquanto o traço aponta para a estrutura da escrita, o significante se articula pela estrutura da língua (Dunker, 2003).

Destacamos que nessa construção do significante o que aparece como condição essencial é esse ato de apagamento de um rastro e o recalcamento do traço. O rastro, enquanto um primeiro nível de substituição, estabelece uma relação de representação daquilo que no real é sua origem. O significante, como operador de linguagem, só pode remeter-se a outro significante em uma relação de representatividade e, estando completamente esvaziado de sentido, não traz nenhuma relação com o objeto (Lacet, 2003).

\section{A letra enquanto litoral: o resto que singulariza o sujeito}

Passemos às últimas conceituações sobre a letra. O texto de Lacan "Lituraterra" (1971/2006) aborda questões fundamentais em torno da diferença entre a fala e a escrita, isto é, entre o significante e a letra, justamente por situá-los em registros absolutamente diferentes. Nessa heterogeneidade a letra aparece como algo de um resto, dimensão que se relaciona profundamente com a discussão construída anteriormente, no sentido da queda de um objeto necessário para compor um registro.

Em "Lituraterra" (1971/2006) ao tratar da escrita do sujeito, ou daquilo que dele se pode escrever, retoma o tema da letra. A etimologia do termo "lituraterra" aponta que Litura (em latim: risco, alteração, mancha, terra) está associado a Littera (referido à letra e à palavra Literatura).

Neste texto, a letra é forjada como um litoral entre o saber (inconsciente) e o gozo, posto que ela separa dois domínios que não têm nada em comum, nem mesmo uma relação recíproca. Não se trata de fazer fronteira entre dois territórios, pois a fronteira, ao separar dois territórios, indicaria que eles são da mesma natureza, sendo somente separados por uma linha demarcatória. A letra, de fato, envolve a radicalidade da diferença de consistências entre o saber, e sua busca em torno da verdade, e o gozo, enquanto inacessível.

A letra seria uma espécie de litoral entre dois registros de naturezas diversas, desenhando ou escrevendo essa borda tão pouco precisa no ser falante. Pensar a relação entre a letra e o inconsciente nos conduz, inevitavelmente, a discutir a posição da letra em face do significante. Lacan é enfático ao dizer que a letra não 
se confunde com o significante, pois "A escritura, a letra, estão no real, o significante, no simbólico" (Lacan, 1971/2006, p. 28).

A partir desse texto, podemos dizer que a função da escrita é abordar o que é da ordem do impossível, permitindo uma reinvenção da realidade. A escrita, tomada como representação de palavras, é, portanto, segunda, cerzida de letras, bordeando o furo no saber, o impossível de escrever. Desse modo, conclui-se que se o traço apaga a Coisa (das Ding), é pelo apagamento do traço que o sujeito é designado (Leite, 2014).

Em “Lituraterra" (1971/2006) e posteriormente em O seminário. Livro 20. Mais ainda (1972-1973/1985), Lacan propõe uma metáfora (as nuvens e a água da chuva que sulca a terra) para estabelecer a relação entre linguagem, letra e significante na produção das inscrições psíquicas. Trazendo essa metáfora para o campo da infância, das primeiras inscrições psíquicas, Jerusalinsky (2014) propõe a seguinte releitura:

A linguagem seria como uma nuvem (estrutura simbólica). Mas não basta a nuvem nem a chuva, enquanto fala materna, para que se produzam efeitos de inscrição na terra (enquanto corpo do bebê). É necessário que a torrente de significado (imaginário) que corre como um rio deposite seus aluviões, esses restos que sulcam, que marcam a terra, tal como a letra que se inscreve. (p. 137)

A letra, enquanto inscrição psíquica no infans, não é anterior ao significante, mas uma precipitação que se processa a partir dele. A letra comparece destacada dessa "nuvem da linguagem", ela precipita, ela chove do semblante (Lacan, 1972-1973/1985, p. 163). Por sua vez, um trabalho de leitura é necessário para que o bebê possa advir como sujeito e a partir daí seja capaz de produzir um saber.

Esse percurso em torno da letra pode ser concluído agora com o seguinte esclarecimento. A letra possui uma duplicidade: em uma vertente, se ela está articulada, pode gerar o sentido; numa outra vertente, estando isolada, comparecendo como resto caído de uma série, ela traz consigo, então, a dimensão do gozo.

\section{$O$ infantil enquanto resto na invenção do sujeito}

Depois desses apontamentos importantes da obra de Lacan, abordaremos a dimensão da coisa perdida e apagada que possibilita que a realidade discursiva possa se estabelecer para o sujeito, a partir do qual ele constrói uma narrativa sobre sua história. É nesse contexto que queremos indagar a relação com o infantil.

A partir da temporalidade lógica do inconsciente, podemos afirmar que o adulto não existe. Nesse sentido é possível pensar que o infantil é para a psicanálise 
uma categoria que aponta para uma estrutura do sujeito, que envolve, por sua vez, uma relação com a falta. Nesse sentido: estaria o conceito de infantil envolvido nesta dimensão de algo que se perde, que se registra e se inscreve enquanto ausência sempre relançada na cadeia psíquica no a posteriori da experiência?

$\mathrm{O}$ inconsciente entrelaça-se com o infantil na medida em que ele é um lugar do gozo, da pulsão e dos significantes. A divisão do sujeito é marca do inconsciente infantil que se dá no plano do significante, mas também no plano do objeto que causa seu desejo, objeto que traria um a mais de gozo perdido.

Retomando o postulado da diferença entre a infância e o infantil, podemos afirmar agora que a infância no campo do registro remete a um tempo que o sujeito julga ter vivido em suas origens e, por isso, trata-se de uma narrativa. $\mathrm{O}$ infantil, por sua vez, enquanto condição estrutural remete a uma perda de gozo necessário para o advento do sujeito. Tal perda de gozo se presentifica através da repetição de uma temporalidade que remete sempre a um tempo do inacabado.

Uma questão fundamental nessa discussão é a possibilidade de articularmos a temática do objeto que precisa ser perdido para que um traço possa advir no lugar dessa falta, possibilitando, assim, que o sujeito possa registrar a perda de gozo, fruto de sua alienação e separação no campo do significante.

\section{Conclusão}

Tendo em vista tais considerações, pensamos que o infantil seria o que ficou como falta naquilo que o sujeito julga ter vivido em suas origens. A infância aparece, por outro lado, como um saber que o sujeito tece no a posteriori através do uso do significante que, por sua vez, substitui os traços recalcados e os rastros apagados das perdas constitutivas. A infância seria, assim, uma escrita, algo que é da ordem de um saber, algo que é possível de ser narrado. Como já indicado, o infantil, apesar de se relacionar a este tempo da infância, não poderia, entretanto, ser reduzido a ele. O infantil na condição de resto, de literal, apresenta uma face não de adjetivo, mas de substantivo, uma face de coisa que ficou faltosa dentro daquilo que se julga ter vivido, estando, portanto, no campo do gozo.

Falar do infantil na psicanálise é falar daquilo que permite ao sujeito o passeio por dois mundos, o mundo da linguagem e da ficção e o mundo do que não ganha palavra, de algo que fica como perda num tempo em que o sujeito não estava lá para se contar e que dita o tom do gozo do sujeito. O infantil se desdobra para o campo da criação, da ficção, da construção de um sujeito situado no tempo, sujeito este que somente num a posteriori pode aparecer como ser da linguagem e situar em suas origens uma falta que o constitui. 
Se a infância pode ser considerada um tempo em que o sujeito se conta e se situa temporalmente através de uma narrativa, propomos que ela deve ser compreendida como esse tempo em que o sujeito produz uma cena de fantasia que tem um valor de saber. Diferentemente da infância, o infantil constitui uma parcela de gozo que escapa dessa narrativa tecida de significante, e por isso propomos que o infantil se articula ao campo da letra.

Em outras palavras, a infância se articula ao relato feito pela cadeia significante, a esta ficção que o sujeito cria para si mesmo, a esta narrativa que tenta contornar o impossível das origens. Por outro lado, o infantil aponta para o impossível, para aquilo que é da ordem da letra, do que promove apagamento e rasura deixando os restos que serão retomados no discurso do sujeito. $\mathrm{O}$ infantil é uma espécie de escritura que não se faz com significantes, mas com objetos perdidos e seus rastros.

\section{Referências}

Costa, A. (2001). Corpo e escrita: relações entre memória e transmissão da experiência. Rio de Janeiro: Relume-Dumará.

Dor, J. (1989). Introdução à leitura de Lacan: o inconsciente estruturado como uma linguagem. Porto Alegre: Artmed.

Dunker, C.I.L. (2003, Diciembre). A importância da topologia na clínica da histeria. O problema da identificação. Acheronta-Revista de Psicoanálisis y Cultura, n. 18.

Fragelli, I. K. Z. (2002). A relação entre escrita alfabética e escrita inconsciente: Um instrumento de trabalho na alfabetização de crianças psicóticas. Dissertação de Mestrado, Instituto de Psicologia, Universidade de São Paulo, São Paulo, SP.

Freud, S. (1996). Projeto para uma psicologia científica. In Edição Standard Brasileira das Obras Psicológicas de Sigmund Freud (v. I). Rio de Janeiro: Imago. (Trabalho original publicado em 1895).

Freud, S. (1996). Carta 52. In Edição Standard Brasileira das Obras Psicológicas de Sigmund Freud (Vol. I). Rio de Janeiro: Imago. (Trabalho original publicado em 1896[1950]).

Jerusalinsky, J. (2014). A criação da criança. Brincar, gozo e fala entre a mãe e o bebê. Salvador: Àgalma.

Lacan, J. (1958-1959). O seminário. Livro 6. O desejo e sua interpretação. Inédito.

Lacan, J. (1961-1962). O seminário. Livro 9. A identificação. Inédito.

Lacan, J. (1973). O seminário. Livro 11. Os quatro conceitos fundamentais da Psicanálise. Rio de Janeiro: Jorge Zahar. (Trabalho original publicado em 1964).

Lacan, J. (1985). O seminário. Livro 20. Mais ainda. Rio de Janeiro: Jorge Zahar, 1985. (Trabalho original publicado em 1972-1973). 
Lacan, J. (1995). O seminário. Livro 4. A relação de objeto. Rio de Janeiro: Jorge Zahar. (Trabalho original publicado em 1956-1957).

Lacan, J. (1998). O seminário sobre "A Carta Roubada". In Escritos (p. 11-66). Rio de Janeiro: Jorge Zahar. (Trabalho original publicado em 1966).

Lacan, J. (1998). A instância da letra no inconsciente ou a razão desde Freud. In Escritos. Rio de Janeiro: Jorge Zahar. (Trabalho original publicado em 1957).

Lacan, J. (1999). O seminário. Livro 5. As formações do inconsciente. Rio de Janeiro: Jorge Zahar. (Trabalho original publicado em 1957-1958).

Lacan, J. (2005). O seminário. Livro 10. A angústia. Rio de Janeiro: Jorge Zahar. (Trabalho original publicado em 1962-1963).

Lacan, J. (2006). O seminário. Livro 18. De um discurso que não seria semblante. Rio de Janeiro: Jorge Zahar. (Trabalho original publicado em 1971).

Lacet, C. (2003). Considerações sobre a Letra e a escrita na clínica psicanalítica. Estilos da Clínica, VIII(14), 50-59.

Leite, S. (2014). Escrita, inscrições e psicose. In A. Costa, \& D. Rinaldi, Linguagem e escritas do corpo. Rio de Janeiro: Companhia de Freud.

Neves, B., \& Vorcaro, A. (2011, ago.). Breve discussão sobre o traço unário e o objeto a na constituição subjetiva. Psicologia em Revista, 17(2), 278-290.

\section{Resumos}

(The infantile in the constitution of the psyche: remains, inscription and narrative)

This article describes the ways of the constitution process of the psyche as an inscription process of traits and the creation of a record. Some fundamental aspects of Lacan's theory were used to that end, such as the lack of object, the trait, the letter, the significant, the repetition, and the jouissance. Our main goal was to demonstrate that in the field of the letter, i.e., the zone between the significant and the jouissance, one may delimit the real status of the term 'infantile' more precisely, in terms of both the theory and the psychoanalytic clinic, thereby distinguishing it from the term 'childhood'.

Key words: Infantile, childhood, inscription, jouissance

(L'infantile dans la constitution subjective : restes, écriture et narration)

Cet article décrit les étapes du processus de la constitution du psychisme comme processus d'inscription de traits et de construction d'un registre. Dans ce but, nous introduisons certains aspects fondamentaux de la théorie lacanienne : le manque de l'objet, le trait, la lettre, le signifiant, la répétition et la jouissance. L'objectif principal de cet article est de démontrer que dans le champ de la lettre, dans le 
littoral entre le signifiant et la jouissance, il est possible de définir très nettement la condition réelle du terme 'infantile', non seulement pour la théorie, mais aussi pour la clinique psychanalytique et de le distinguer du terme 'enfance'.

Mots clés: Infantile, enfance, inscription, jouissance

(El infantil en el proceso de la constitución subjetiva: restos, escritura y narrativa)

El artículo describe la senda del proceso de constitución del psiquismo como un proceso de inscripción de trazos y de la construcción de un registro. Para ello, se introducen algunos aspectos fundamentales de la teoría de Lacan: la falta del objeto, el trazo, la letra, el significante, la repetición y el gozo. El objetivo principal es demostrar que, en el campo de la letra, en la margen entre el significante y el gozo, es posible delimitar con mayor precisión la verdadera constitución de la noción de infantil, para la teoría y para la clínica psicoanalítica, distinguiéndolo, simultáneamente, de la noción de infancia.

Palabras clave: Infantil, infancia, inscripción, gozo

(Das Infantile in der subjektiven Konstituition: Spuren, Schreiben und Erzählung)

Dieser Artikel beschreibt die Wege des Aufbauprozesses der Psyche als Inskription von Zügen und Erstellung eines Verzeichnisses. Zu diesem Zweck werden einige der wichtigsten Aspekte der Theorie Lacans eingeführt: Objektmangel, der Zug, der Buchstabe, der Signifikant, die Wiederholung und das Genießen. Dieser Artikel will an erster Stelle aufzeigen, dass es im Bereich des Buchstabens - in der Grauzone zwischen dem Signifikant und dem Genießen - möglich ist, den realen Stellenwert des Begriffs 'Infantil' für die Theorie und die psychoanalytische Klinik zu definieren und ihn gleichzeitig vom Begriff 'Kindheit' zu unterscheiden.

Schlüsselwörter: Infantil, Kindheit, Inskription, Genießen

（童年在主观的构成: 遗体、书写和叙述）

本文介绍了心灵建设过程的途径, 例如印象的痕迹和记录的建立。因此需 要引入拉康的理论中的一些基本理念: 对象的缺乏, 痕迹, 字, 能指, 重复和享 受。其主要目的是论证在此属于能指和享受的交界处的 “字” 领域可以更准确的 定下童年在理论和精神临床的实际地位, 而从此区分童年的概念。

关键词: 贞儿, 童年, 题字, 享受 


\section{ARTIGO}

Citação/Citation: Costa, G. Q., Leite, S. (2015, dezembro). O infantil na constituição subjetiva: restos, escrita e narrativa. Revista Latinoamericana de Psicopatologia Fundamental, 18(4), 619-633.

Editores do artigo/Editors: Prof. Dr. Manoel Tosta Berlinck e Profa. Dra. Sonia Leite

Recebido/Received: 25.11.2014/ 11.25.2014 Aceito/Accepted: 14.12.2014 / 12.14.2014

Copyright: (C) 2009 Associação Universitária de Pesquisa em Psicopatologia Fundamental/ University Association for Research in Fundamental Psychopathology. Este é um artigo de livre acesso, que permite uso irrestrito, distribuição e reprodução em qualquer meio, desde que o autor e a fonte sejam citados / This is an open-access article, which permits unrestricted use, distribution, and reproduction in any medium, provided the original authors and sources are credited.

Financiamento/Funding: $\mathrm{O}$ autores declaram não ter sido financiados ou apoiados / The authors have no support or funding to report.

Conflito de interesses/Conflict of interest: $\mathrm{O}$ autores declaram que não há conflito de interesses / The authors have no conflict of interest to declare.

\section{Germano Quintanilha Costa}

Psicólogo; Psicanalista; Professor Assistente do Curso de Psicologia da Universidade Federal Fluminense (Polo de Campos dos Goytacazes, RJ, Br); Doutorando do Programa de Psicanálise da Universidade do Estado do Rio de Janeiro - UERJ (Rio de Janeiro, RJ, Br); Membro do Corpo Freudiano Escola de Psicanálise - Seção Campos dos Goytacazes.

Rua Acir Bastos, 33/604 - Centro

28010-130 Campos dos Goytacazes, RJ, Br

e-mail: gqcost@yahoo.com.br

\section{Sonia Leite}

Psicóloga; Psicanalista; Professora Visitante do Programa de Pós-Graduação em Psicanálise da Universidade do Estado do Rio de Janeiro - UERJ (Rio de Janeiro, RJ, Br); Coordenadora Adjunta da Residência Multiprofissional em Saúde Mental CPRJ/UERJ (Rio de Janeiro, RJ, Br); Membro do Corpo Freudiano Escola de Psicanálise - Seção RJ; Membro da Associação Universitária de Pesquisa em Psicopatologia Fundamental - AUPPF (São Paulo, SP, Br).

Rua Conde de Bonfim, 289/702 - Tijuca

20520-051 Rio de Janeiro, RJ, Br

e-mail: soniacleite@uol.com.br

\section{(cc) BY-NC}

This is an open-access article, which permits unrestricted use, distribution, and reproduction in any medium for non-commercial purposes provided the original authors and sources are credited. 